\title{
Analysis of salts for use as support structure in metal material jetting
}

\author{
Benedikt Kirchebner ${ }^{1}\left[\right.$ (]) Christoph Rehekampff ${ }^{2} \cdot$ Martin Tröndle $^{1}\left(\mathbb{D} \cdot\right.$ Philipp Lechner $^{1}\left(\mathbb{D} \cdot\right.$ Wolfram Volk $^{1}(\mathbb{C})$
}

Received: 22 February 2021 / Accepted: 20 April 2021 / Published online: 10 May 2021

(c) The Author(s) 2021

\begin{abstract}
Material jetting (MJT) is a category of additive manufacturing processes where the build material is deposited in the form of individual droplets. MJT has recently been expanded into the field of metal processing due to a potentially high printing speed at low equipment and raw material cost. For full 3D capability, support structures are needed that have to be removed after the print job. We examine water soluble salts and suitable nozzle materials to realise the printing of molten salt in a MJT process. Here, the wetting characteristics of the melt and nozzle are crucial because pronounced wetting is problematic for the ejection of droplets. A sessile-drop contact angle test stand was set up to evaluate the wetting characteristics of three salts or salt mixtures $\left(\mathrm{NaCl}, \mathrm{KCl}-\mathrm{NaCl}\right.$ and $\mathrm{NaCl}-\mathrm{Na}_{2} \mathrm{CO}_{3}$ ) on six different nozzle materials (various ceramics and graphite), i.e. potential nozzle materials. The results indicate a high wetting tendency of most of the examined samples with the exception of $\mathrm{KCl}-\mathrm{NaCl}$ on graphite. Application of these materials on a MJT test stand confirm the feasibility of our findings.
\end{abstract}

Keywords Additive manufacturing $\cdot$ Material jetting $\cdot$ Salts $\cdot$ Support structure $\cdot$ Wetting $\cdot$ Contact angle

\section{Introduction}

Industry has many demands on production technologies: low cost, high volume, high possible part complexity and short time from idea to production, just to name a few. If the latter two are the priority, additive manufacturing (AM) techniques offer many advantages compared to conventional production technologies. Many different AM processes have been developed in the last few decades and the processable materials are increasing rapidly. Today, a selection of polymers, metals, ceramics and composite materials can be processed additively [1].

In the world of metal AM, the powder bed fusion processes have gained a lot of attention. Metal powder is selectively melted with lasers or electron beams to create three

Benedikt Kirchebner

benedikt.kirchebner@utg.de

Christoph Rehekampff

christoph.rehekampff@tum.de

1 Technical University of Munich, Chair of Metal Forming and Casting, Walther-Meissner-Str. 4, 85748 Garching, Germany

2 Technical University of Munich, Institute of Micro Technology and Medical Device Technology, Boltzmannstr. 15, 85748 Garching, Germany dimensional parts. In 2019 the majority of AM systems for metallic parts were based on the powder bed fusion (PBF) process [1].

However, the terms low cost and high volume can not be attributed to the PBF technologies. Another approach for producing metal parts additively is material jetting (MJT). Molten droplets of metal are ejected onto a heated build platform and bond. This results in dense metal parts with mechanical properties that can be better than those of the cast reference due to high cooling rates [2]. The inexpensive raw materials in the form of metal wire combined with the low equipment cost and potentially high printing speed are the main attractions of this technology. In industry, this process is currently mainly used for photopolymers and waxlike materials [1]. However, there has already been research conducted on expanding the printable materials into the field of aluminium alloys. Liu et al. [3] presented a piezo actuated continuous jet print head, Karampelas et al. [4] developed a magnetohydrodynamic drop-on-demand print head and Himmel et al. examined the tensile properties of specimens printed from an aluminium silicon alloy [2].

The shapes that can be directly produced by just adding droplets onto a moving build platform are limited. For more shapes with overhanging structures, multi-axial movement of the platform, support structures, or both are needed. The present investigation shows an approach for 
easily removable support structures in metal MJT. The printing of salts shall be enabled to create water soluble structures that endure the temperature of molten aluminium. Regarding the target droplet size, two effects have to be considered. Obviously, the droplet size directly affects the resolution of the printed part and therefore, a small droplet diameter would be desirable. However, the droplet diameter has a strong impact on the printing speed since the droplet volume is proportional to the third power of the diameter. Taking this into account, we target a droplet size of $500 \mu m$.

For the material selection of nozzle and support material, the wetting characteristics are of importance. High wettability makes it very hard for the printing process to work reliably since the underside of the nozzle is covered with fluid which hinders a proper ejection of droplets. However, we hypothesise that there is a combination of salt and nozzle material that shows low wettability and therefore enables the processing of the salt in a MJT print head. Since there is little research on the wetting of salts on any surface, a contact angle test stand was built and various combinations of ceramic or graphite surfaces and selected salt melts were tested to determine pairs that show high contact angles. The contact angles are directly linked to the wettability. The implementation of salt MJT shall ultimately result in less post processing in metal MJT.

Figure 1 shows a flow chart of the conducted practice. The salt and nozzle material selection is interrelated through the corrosiveness of the salts and corrosion resistance of the ceramics. Inadequate salts (toxic, very hygroscopic, unsuitable melting temperature, ...) are excluded right away. The wettability of the remaining materials is determined pairwise in a contact angle test stand. Trials on a MJT test stand show the feasibility of salt MJT.

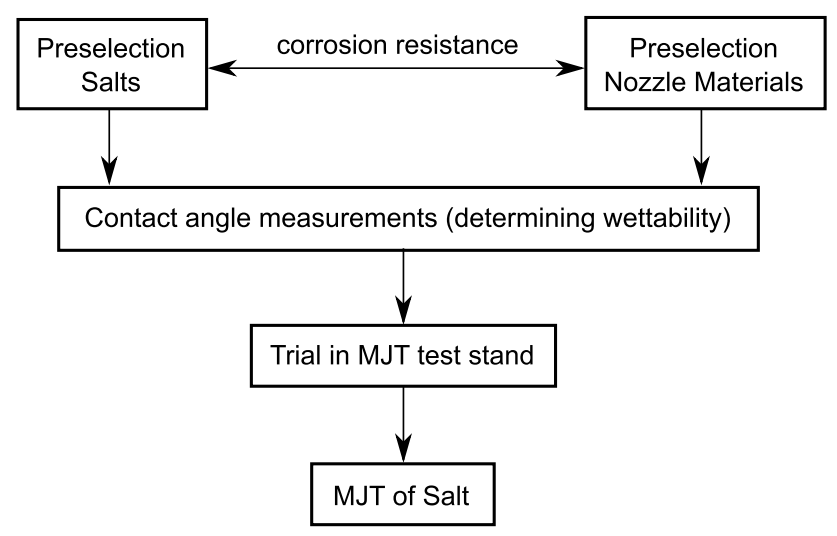

Fig. 1 Flow chart of the conducted practice. The material selection (salt and nozzle material) is followed by contact angle measurements to determine the wettability and concluded by trials on a MJT test stand

\section{State of the art and theoretical background}

\subsection{Support structures for MJT}

Support structures create the basis for overhangs. Figure 2 shows a schematic representation of a material jetted part with support structures. The build material (e.g. aluminium) is shown in black, the support structure in light grey. The heated platform onto which the droplets are ejected is shown in dark grey. The support structures constitute the basis for layers of build material on top of them.

Typically, the support structures are removed after the printing process. This is especially cumbersome when they are hard to access and made from tough materials. Some processes already use dissolvable materials for their support or materials with lower melting temperature than the build material to be removed thermally [1]. Inclined surfaces often also require support structures. In MJT, inclines of more than $45^{\circ}$ from the vertical typically need to be supported [5].

\subsection{Wettability and contact angle}

When a solid, a liquid and a vapour phase come into contact, the contact angle $\theta$ can be observed (see Fig. 3). $\theta$ depends on the surface tensions $\gamma$ of the phases and is described by Young's equation (Eq. 1) [6]. In reality, however, the contact angles will also depend on many other

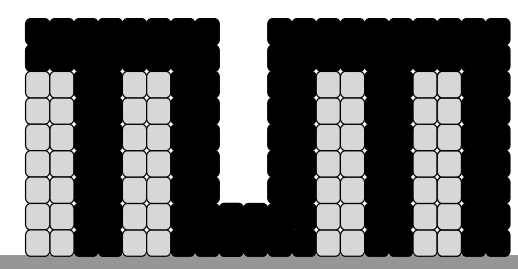

Fig. 2 Schematic representation of a part manufactured with MJT. Black areas designate the printed part, light grey areas the support structure and dark grey areas the heated build platform

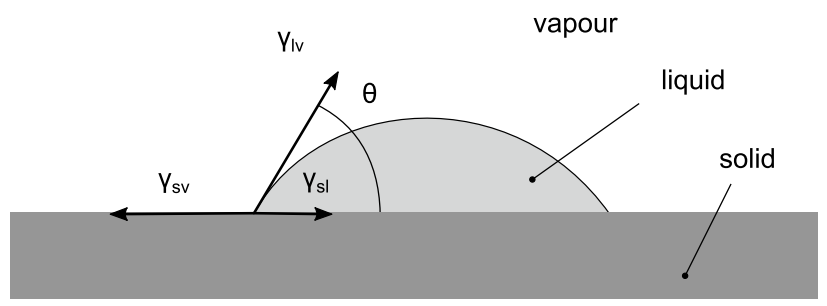

Fig. 3 Droplet on solid surface surrounded by a vapour phase. The surface tension vectors $\gamma_{\mathrm{sv}}, \gamma_{\mathrm{sl}}, \gamma_{\mathrm{lv}}$ define the value of the contact angle $\theta$ according to Eq. 1 [6] 
factors, such as gravity, the droplet volume, the method of dispensing, the ambient temperature, etc. Further, different angles can be observed for the advancing and receding contact angle $\theta_{\mathrm{a}}$ and $\theta_{\mathrm{r}}$ in the case of changing droplet volume during the measurement [7].

$\cos \theta=\frac{\gamma_{\mathrm{sv}}-\gamma_{\mathrm{sl}}}{\gamma_{\mathrm{lv}}}$

where $\theta$ is the contact angle, $\gamma_{\mathrm{sv}}$ the surface tension between solid and vapour phase, $\gamma_{\mathrm{sl}}$ the interfacial tension between solid and liquid phase and $\gamma_{\mathrm{lv}}$ the surface tension between liquid and vapour phase.

According to the value of $\theta$, the wettability is typically divided into four cases, shown in Fig. 4. Very good wetting is the case when the contact angle is very small $(\theta \leq$ $10^{\circ}$ ). Relative to the volume of the fluid, a large area of the substrate is covered with the fluid. A contact angle of $10^{\circ}<\theta \leq 80^{\circ}$ is as sign of good wetting. Poor wetting is defined by a contact angle of $80^{\circ}<\theta \leq 140^{\circ}$. Contact angles $\theta>140^{\circ}$ are observable in case of very poor wetting. Poor or very poor wetting is the state that we aim for when designing nozzles for MJT. High wettability makes printing nearly impossible because the underside of the nozzle covers with fluid and no defined and consistent droplets can be ejected.

\section{Materials and methods}

\subsection{Sample description}

\subsubsection{Preselection salts}

In this work, three different salts or salt mixtures are examined for their suitability as support material (see Table 1). (a)

(c)

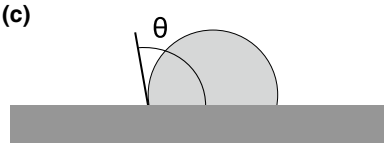

poor wetting $80^{\circ} \leq \theta \leq 140^{\circ}$

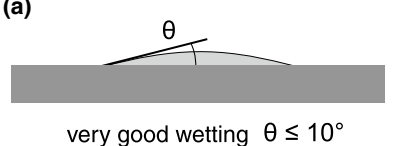

(b)

(d)

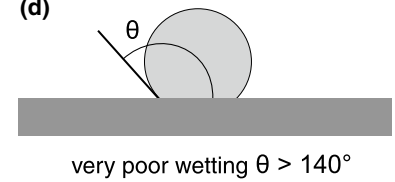

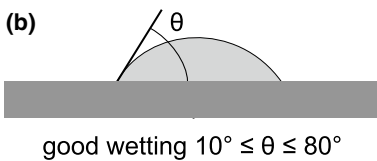

Fig. 4 Classification of contact angle ranges according to [6]. Very good (a) and good wetting (b) of a nozzle by the fluid makes printing nearly impossible. Poor (c) or very poor wetting (d) is the state that we aim for when selecting the nozzle and support material

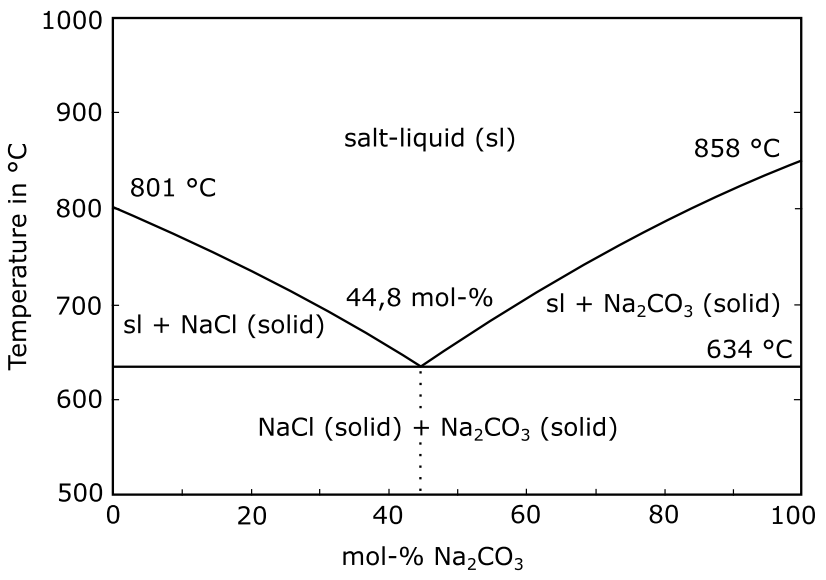

Fig. 5 Phase diagram of $\mathrm{NaCl}$ and $\mathrm{Na}_{2} \mathrm{CO}_{3}$. The melting temperature of the eutectic mixture is $634{ }^{\circ} \mathrm{C}$ and lies significantly below those of the pure salts. [12]

For the selection of these salts their availability, melting temperature, solubility in water, hygroscopicity and environmental aspects were considered.

Due to generally good availability alkali chlorides and alkali carbonates were considered in the preselection. Environmentally harmful and toxic salts, as well as compounds with the radioactive alkali metals or halogens are excluded. The lithium salts are also excluded, since lithium chloride shows high hygroscopic behaviour [8] and lithium carbonate displays poor solubility in water [9]. This leaves the four salts sodium chloride $(\mathrm{NaCl})$, potassium chloride $(\mathrm{KCl})$, sodium carbonate $\left(\mathrm{Na}_{2} \mathrm{CO}_{3}\right)$ and potassium carbonate $\left(\mathrm{K}_{2} \mathrm{CO}_{3}\right)$.

The melting temperature, or temperature range in the case of salt mixtures, is an essential material property for processing. It must be suitable for the respective range of the build material. If the selected salt has a too high melting temperature, the already printed aluminium layer will melt. If the melting temperature is too low, already printed support structures are melted by newly applied aluminium. In our

Table 1 Selected salts for the contact angle measurements

\begin{tabular}{|c|c|c|}
\hline Salt/salt mixture & Melting temperature & Note \\
\hline $\mathrm{NaCl}$ & $801{ }^{\circ} \mathrm{C}[11]$ & Purity: p.a.* \\
\hline $\mathrm{KCl}-\mathrm{NaCl}$ & $658^{\circ} \mathrm{C}[13]$ & $\begin{array}{l}\text { Eutectic } \\
\text { mixture, com- } \\
\text { ponents with } \\
\text { purity: p.a.* }\end{array}$ \\
\hline $\mathrm{NaCl}-\mathrm{Na}_{2} \mathrm{CO}_{3}$ & $634^{\circ} \mathrm{C}[14]$ & $\begin{array}{l}\text { Eutectic } \\
\text { mixture, com- } \\
\text { ponents with } \\
\text { purity: p.a.* }\end{array}$ \\
\hline
\end{tabular}

*Pro analysis, purity: $\geq 99.5 \%$ 
case, the build material is AlSi12 - the eutectic aluminium silicon alloy. AlSi12 melts in a range of $577{ }^{\circ} \mathrm{C}$ to $582{ }^{\circ} \mathrm{C}$ [10]. The processing temperature typically is $700{ }^{\circ} \mathrm{C}$. The salts were selected to have a melting or liquidus temperature of approximately $100{ }^{\circ} \mathrm{C}$ below and above the processing temperature. $\mathrm{NaCl}$ and $\mathrm{KCl}$ fall into this range with melting temperatures of $801{ }^{\circ} \mathrm{C}$ and $770{ }^{\circ} \mathrm{C}$, respectively. The sodium and potassium carbonates, however, show higher melting temperatures with $851{ }^{\circ} \mathrm{C}$ and $901{ }^{\circ} \mathrm{C}$, respectively [11]. The melting or liquidus temperature can be lowered if salts are mixed. A eutectic mixture of $\mathrm{NaCl}$ and $\mathrm{Na}_{2} \mathrm{CO}_{3}$ for example, has a liquidus temperature of $634{ }^{\circ} \mathrm{C}$ (see Fig. 5). An advantage of using mixtures of salts instead of pure salts is that the solidification interval, i.e. the range between solidus and liquidus temperature, can be varied by adjusting the mixing ratio. A eutectic mixture of $\mathrm{KCl}$ and $\mathrm{NaCl}$ and a eutectic mixture of $\mathrm{NaCl}$ and $\mathrm{Na}_{2} \mathrm{CO}_{3}$ were chosen as candidates for the salt support structure. $\mathrm{KCl}$ was excluded in the selection because of the caking tendency in preliminary experiments due to its hygroscopic behaviour. Table 1 shows an overview of the selected salts for the contact angle measurements.

\subsubsection{Preselection nozzle materials}

In order to identify suitable materials for the nozzle, various ceramics and graphite are tested. The samples for the contact angle measurement are typically specimens made of the corresponding nozzle material rather than actual nozzles. Therefore, the nozzle material will, more generally, also be called the substrate material and the specimen itself the substrate. Table 2 shows an overview of the examined substrate materials. One of the main difficulties in handling salt melts in a print head is their typically strong tendency to corrode other materials. This is observable for many metals $[15,16]$. Ceramics are typically more endurant [17] although they are not completely resistant to corrosion [18]. The melting temperatures of the selected salts also demand high temperature resistance. The selection of the tested substrate materials includes five ceramic materials commonly used in industry as well as graphite.
The graphite used is a mineral that is characterised by high temperature resistance, resistance in highly corrosive environments and good machinability. The manufacturer's designation is R7340 (Final Advanced Materials $\mathrm{GmbH}$, Freiburg, Germany). The graphite is isostatically pressed and shows a porosity of $15 \%$. Aluminium oxide is a sintered ceramic that is generally non-porous and has the chemical formula $\mathrm{Al}_{2} \mathrm{O}_{3}$. It can be exposed to temperatures as high as $16500^{\circ} \mathrm{C}$ and has a high thermal conductivity of up to $37 \mathrm{~W} /(\mathrm{mK})$. The specimens are manufactured using LithaLox HP350D (Lithoz GmbH, Vienna, Austria), a ceramic-loaded liquid for Lithography-based Ceramic Manufacturing (LCM). SHAPAL ${ }^{\mathrm{TM}}$ HI M-SOFT (Tokuyama co., Tokyo, Japan) is a machinable aluminium nitride ceramic. It can be used up to $1900{ }^{\circ} \mathrm{C}$ under non-oxidising atmospheres and has good thermal conductivity properties. The material is electrically non-conductive as well as practically non-porous. Silicon nitride, in this case a hot-pressed compound with the designation SN-HP (FCT Ingenieurkeramik GmbH, Frankenblick, Germany), is typically used in foundry technology and chemical apparatus construction. The material shows a thermal conductivity of $22 \mathrm{~W} /(\mathrm{mK})$. Vitronit ${ }^{\circledR}$ is a machinable mica glass ceramic from VITRON Spezialwerkstoffe $\mathrm{GmbH}$, Jena-Maua, Germany. It is practically pore-free, does not degas during heating and can be used for temperatures up to $1000{ }^{\circ} \mathrm{C}$. Vitronit ${ }^{\circledR}$ is a compound of $\mathrm{SiO}_{2}, \mathrm{Al}_{2} \mathrm{O}_{3}$, $\mathrm{MgO}, \mathrm{K}_{2} \mathrm{O}, \mathrm{Na}_{2} \mathrm{O}$ and fluorine. Zirconium oxide is a white sintered ceramic with the chemical formula $\mathrm{ZrO}_{2}$. It is used in medical prosthesis construction and oxygen sensors. We use StarCeram ${ }^{\circledR}$ Z-Smile Pure from KYOCERA Fineceramics Precision GmbH, Selb, Germany.

The surface roughness $R z$ of the samples was examined with a Keyence VK X150 laser microscope. For each sample ten measurements are conducted. The mean $\left(R z_{\text {mean }}\right)$, maximum $\left(R z_{\max }\right)$ and minimum $\left(R z_{\min }\right)$ values aswell as the standard deviation $\left(R z_{\mathrm{sd}}\right)$ are stated in Table 3.

Table 2 Tested substrate (nozzle) materials

\begin{tabular}{lll}
\hline Material & Abbr. & Trade name, manufacturer \\
\hline Aluminium oxide & AO & LithaLox HP350D, Lithoz GmbH, Vienna, Austria \\
Machinable aluminium nitride ceramic & AN & SHAPAL ${ }^{\text {TM }}$ HI M-SOFT, Tokuyama co., Tokyo, Japan \\
Isostatic, machinable graphite & GR & R7340, Final Advanced Materials GmbH, Freiburg, Germany \\
Mica glass ceramic & GC & Vitronit $^{\circledR}$, VITRON Spezialwerkstoffe GmbH, Jena-Maua, Germany \\
Silicon nitride & SN & SN-HP, FCT Ingenieurkeramik GmbH, Frankenblick, Germany \\
Zirconium dioxide & ZO & StarCeram ${ }^{\circledR}$ Z-Smile Pure, KYOCERA Fineceramics Precision \\
& & GmbH, Selb, Germany \\
\hline
\end{tabular}


Table 3 Surface roughness of the samples for the contact angle measurements

\begin{tabular}{lllll}
\hline & $R z_{\text {mean }}$ & $R z_{\text {max }}$ & $R z_{\text {min }}$ & $R z_{\text {sd }}$ \\
\hline AO & 11,1 & 15,4 & 8,7 & 1,7 \\
AN & 11,7 & 13,2 & 9,5 & 1,0 \\
GR & 11,7 & 23,8 & 9,1 & 2,9 \\
GC & 22,2 & 33,4 & 14,0 & 5,9 \\
SN & 15,1 & 18,6 & 12,3 & 1,5 \\
ZO & 7,9 & 10,3 & 6,3 & 1,1 \\
\hline
\end{tabular}

$R z$ in $\mu \mathrm{m}$

\subsection{Experimental setup}

\subsubsection{Test stand for MJT}

The test stand, developed for the printing of aluminium, has been previously described in detail by Himmel et al. [2] and Rumschoettel et al. [19]. Figure 6 shows a schematic view of the test stand. The printing chamber is purged with nitrogen, which is also used for ejecting the droplets. A pressure surge is created by a solenoid valve. The print head sits on top of the chamber and mainly consists of the ceramic crucible, heating elements and the nozzle. The test stand is controlled by a programmable logic controller (PLC) via a human machine interface (HMI).

The new print head, designed for the printing of salt, features ceramic heating elements (BACH Resistor Ceramics $\mathrm{GmbH}$, Seefeld, Germany) and a new nozzle material whose selection is described in this paper. In comparison to the nozzle for printing aluminium, the nozzle diameter is

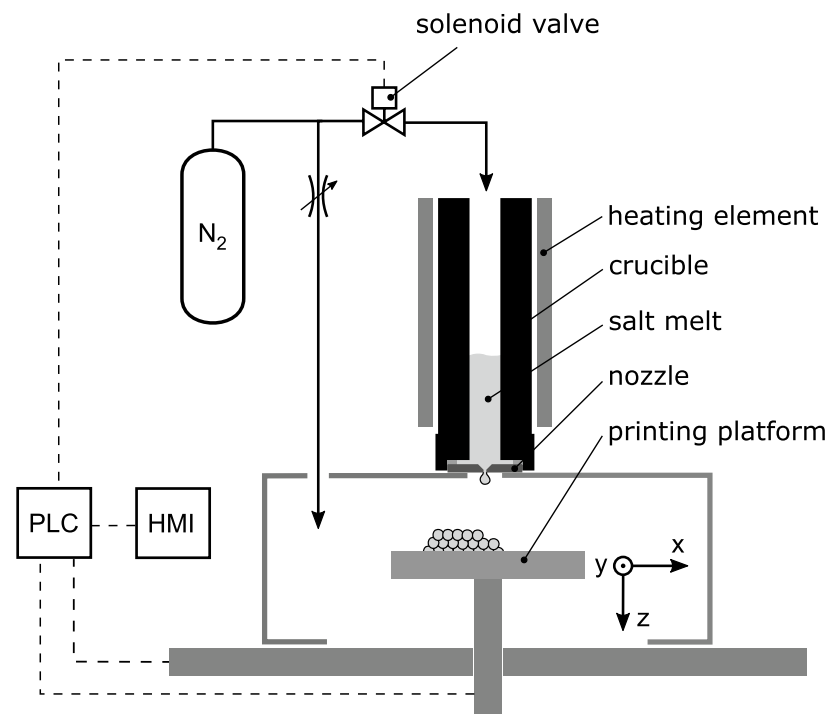

Fig. 6 Schematic view of the MJT test stand for salt melts. The salt melt is located in the heated crucible. Droplets are ejected onto the heated printing platform via a pressure surge. The printing platform is located in a nitrogen purged chamber and can be controlled by a PLC

reduced to $100 \mu \mathrm{m}$ because preliminary experiments showed leakage for greater diameters. The resulting droplet size heavily depends on the opening time of the solenoid valve and is typically in the range of $490 \mu \mathrm{m}$ to $780 \mu \mathrm{m}$ for valve opening times of $2 \mathrm{~ms}$ to $8 \mathrm{~ms}$ at a pressure of $2 \mathrm{bar}$. The droplets flatten upon impact, showing a height that is typically $30 \%$ of the lateral extension.

A mica sealing is placed between crucible and nozzle (Final Advanced Materials GmbH, Freiburg, Germany). Pneumatic impulses force the liquid through the nozzle, resulting in the formation of droplets.

\subsubsection{Contact angle test stand}

To determine the wetting, the sessile drop method is used in this work. Salt is placed on the substrate material and heated up until fully melted. Figure 7 schematically shows the basic principle of the method. In the centre of the test stand is a copper rod that transfers heat from the heating elements to the specimens. The heating elements are ceramic fibre heaters (Watlow Electric Manufacturing Co., St. Louis, United States) and are controlled using a Watlow EZ-Zone ${ }^{\circledR}$ PM6 PID controller. Inside the top of the copper rod is a thermocouple for closed loop temperature control. The copper rod is enclosed by borosilicate glass that enables optical inspection of the specimens. The test chamber is purged with nitrogen to prevent oxidation of the copper rod, to ensure consistent experimental conditions and to create a low-oxygen environment such as in the later application. Images of the droplets are captured by a digital camera (Lu170M, Teledyne Lumenera, Ottawa, Canada). A monochrome 1.3 megapixel image sensor is used in combination with a M118FM16 lens

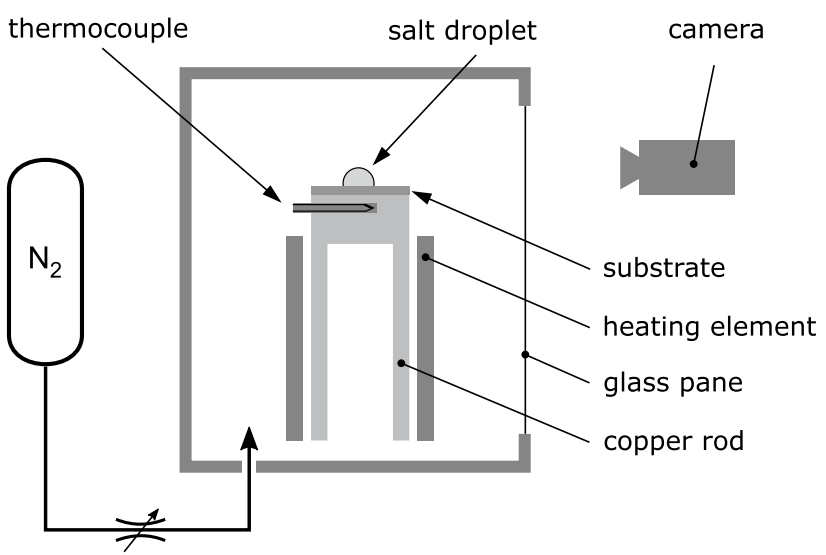

Fig. 7 Schematic view of the test stand used for determining contact angles. The sample (salt droplet on substrate) is located on top of a heated copper rod. The surrounding chamber is purged with nitrogen. A camera outside of the chamber is observing the sample through a glass pane 
(TAMRON Co.,Ltd., Saitama, Japan). For image analysis, the software ImageSP (TRS, Dünzelbach, Germany) is used. An external illumination of the sample as used in previous experiments [20] can be omitted, since the operation temperatures lead to radiation in the visible spectrum. Limitations of the sessile drop method are that the measurement is, amongst others, influenced by substrate surface inhomogeneity and gravity [7].

\subsection{Experimental procedure for determining the contact angle}

For determining the contact angle of a surface-salt pair, the specimen (salt on substrate) is first placed on the copper rod. Next, the chamber is purged with Nitrogen 5.0 (Linde plc, Dublin, Ireland) at a flow rate of $2.51 / \mathrm{min}$ for five minutes. Afterwards, the heater is turned on and heats the specimen up to the salt-specific melting temperature while the nitrogen purging is maintained. Once the salt begins to melt, this temperature is maintained. When the specimen is completely melted, the heating is turned off. An image with the salt completely molten is used to determine the contact angle. Nitrogen purging is stopped after the temperature of the copper rod falls below $100{ }^{\circ} \mathrm{C}$. The contact angles are determined manually by aligning a tangent in the three-phase point. The angle is determined on both sides of the droplet which leads to two possibly different results per measurement.

Due to a hypothesised dependence of the contact angle $\theta$ of both the salt and the substrate material, a full factorial design is chosen over a fractional factorial design. Because of the high experimental effort, only one saltsubstrate combination $(\mathrm{NaCl}$ on $\mathrm{AN})$ is measured three times to determine a representative statistical range of the measurements. The measurements of all other combinations are executed once.

Table 4 Results of the contact angle measurements

\begin{tabular}{llll}
\hline & $\mathrm{NaCl}$ & $\mathrm{KCl}-\mathrm{NaCl}$ & $\mathrm{NaCl}-\mathrm{Na}_{2} \mathrm{CO}_{3}$ \\
\hline $\mathrm{AO}$ & $5 / 6$ & $10 / 10$ & $<5$ \\
$\mathrm{AN}$ & $63^{*}$ & $43 / 57$ & $17 / 19$ \\
$\mathrm{GR}$ & $19 / 24$ & $75 / 87$ & $13 / 15$ \\
$\mathrm{GC}$ & $<5$ & $<5$ & $17 / 17$ \\
$\mathrm{SN}$ & $<5$ & $23 / 26$ & $11 / 12$ \\
$\mathrm{ZO}$ & $<5$ & $<5$ & $<5$ \\
\hline
\end{tabular}

Contact angle $\theta$ in $^{\circ}$

*Rounded mean value of three individual measurements, thus six contact angles. Individual values: 60/62, 54/60, 70/73. Statistical range $\mathrm{R}=19^{\circ}$

\section{Results and discussion}

\subsection{Contact angle measurements}

Table 4 shows the experimental results of the contact angle measurements. The examined droplets' volumes are in the range of $25 \mu \mathrm{l}$ to $63 \mu \mathrm{l}$.

The left and right contact angle are separated by a slash $\left(\theta_{\text {left }} / \theta_{\text {right }}\right)$ and do not necessarily need to match, e.g. due to surface inhomogeneity. Many salt-substrate pairs show very good wetting with barely observable contact angles $\theta<5^{\circ}$. This applies for all $\mathrm{ZO}$ combinations. AO and GC also show very good wetting with all salts, the combination of $\mathrm{GC}$ and $\mathrm{NaCl}-\mathrm{Na}_{2} \mathrm{CO}_{3}$ being the only exception at $\theta=17^{\circ} / 17^{\circ}$. The wetting characteristic of the remaining substrates heavily depends on the applied salt. In SN for example, very good wetting is only observed in combination with $\mathrm{NaCl}$. The combinations of $\mathrm{SN}$ with $\mathrm{KCl}-\mathrm{NaCl}$ and $\mathrm{NaCl}-\mathrm{Na}_{2} \mathrm{CO}_{3}$ only show good wetting at $\theta=23^{\circ} / 26^{\circ}$ and $\theta=11^{\circ} / 12^{\circ}$, respectively. Higher contact angles are observable on AN with $\mathrm{KCl}-\mathrm{NaCl}\left(\theta=43^{\circ} / 57^{\circ}\right)$ and $\mathrm{NaCl}-\mathrm{Na}_{2} \mathrm{CO}_{3}\left(\theta=17^{\circ} / 19^{\circ}\right)$. The contact angle of the combination $\mathrm{AN}$ with $\mathrm{NaCl}$ was measured three times. The individual results are $60^{\circ} / 62^{\circ}$, $54^{\circ} / 60^{\circ}$ and $70^{\circ} / 73^{\circ}$. The mean contact angle is $\theta \approx 63^{\circ}$ and the statistical range is $\mathrm{R}=19^{\circ}$. The highest contact angle in all samples and poor wetting was observed for $\mathrm{KCl}-\mathrm{NaCl}$ on GR $\left(\theta=75^{\circ} / 87^{\circ}\right)$. In Fig. 8 four representative images of the contact angle measurements are shown. Molten $\mathrm{KCl}-\mathrm{NaCl}$ on different substrates are displayed. $\mathrm{ZO}$ is very well wetted with the salt melt (a). Good wetting is observable on SN (b) and AN (c). Poor wetting can be determined on GR (d).

We suspect that the contact angles do change over time in our setup after initial melting of the sample, even at constant copper rod temperature and nitrogen flow rate so two extended measurements were performed. A change in (a)

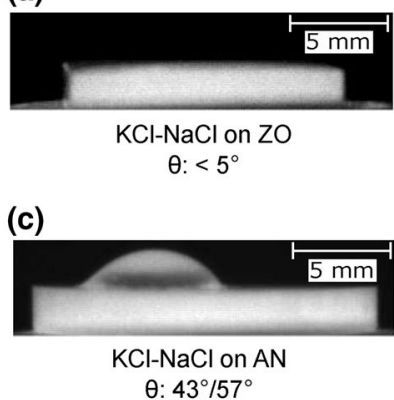

(b)

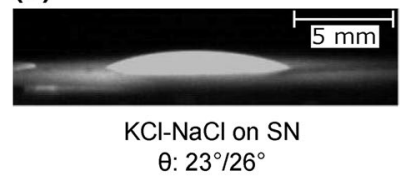

(d)

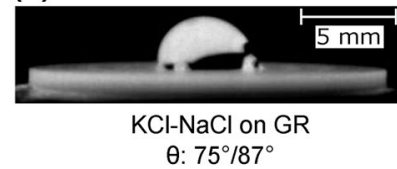

Fig. 8 Results of the contact angle measurements $\mathrm{KCl}-\mathrm{NaCl}$ on $\mathrm{ZO}$, $\mathrm{SN}, \mathrm{AN}$ and GR. The highest contact angle in all samples and poor wetting was observed for $\mathrm{KCl}-\mathrm{NaCl}$ on $\mathrm{GR}\left(\theta=75 / 87^{\circ}\right)$ 
contact angle can, for example, occur by chemical reaction of salt and substrate material or salt mass reduction due to evaporation [7]. An evaporation of the sample leads to liquid volume reduction, thus evoking a drawback of the three-phase point leading to a receding contact angle $\theta_{\mathrm{r}}$. Furthermore, the substrate and/or salt temperature might also increase due to a maintained heat flux from the copper rod. A constant copper rod temperature does not necessarily imply a constant substrate temperature. A long term measurement of $\mathrm{NaCl}$ on $\mathrm{AN}$ showed varying contact angles over time, ranging from about $70^{\circ}$ just after the salt is completely melted to $20^{\circ}$ after $20 \mathrm{~min}$ at quasi constant temperature of the copper rod and nitrogen flow rate. After 37min a distinct droplet can no longer be observed (Fig. 9). For $\mathrm{KCl}-\mathrm{NaCl}$ on GR, a long term measurement was performed, too. A decline in contact angle from approximately $85^{\circ}$ to $20^{\circ}$ was observable $40 \mathrm{~min}$ after the salt was completely melted. The droplet is no longer observable after an additional $14 \mathrm{~min}$.

It is apparent that the contact angle depends on both the salt and the substrate. $\mathrm{KCl}-\mathrm{NaCl}$, for example, shows very good wetting on GC but poor wetting on GR. GC is wetted by $\mathrm{NaCl}$ and $\mathrm{KCl}-\mathrm{NaCl}$ with $\theta<5^{\circ}$ and by $\mathrm{NaCl}-\mathrm{Na}_{2} \mathrm{CO}_{3}$ with $\theta=17^{\circ}$.

\subsection{Trial in MJT test stand}

Nozzles were manufactured out of selected substrate materials and tested in the MJT test stand. Table 5 gives an overview of the tested combinations. The two combinations with the highest contact angles ( $\mathrm{KCl}-\mathrm{NaCl}$ on $\mathrm{GR}$ and $\mathrm{NaCl}$ on $\mathrm{AN}$ ) and two combinations with the lowest observed contact angles ( $\mathrm{KCl}-\mathrm{NaCl}$ on $\mathrm{ZO}$ and $\mathrm{NaCl}-\mathrm{Na}_{2} \mathrm{CO}_{3}$ on $\left.\mathrm{ZO}\right)$ were selected for the experiments. Further, two combinations with contact angles in-between the extreme values $\left(\mathrm{NaCl}-\mathrm{Na}_{2} \mathrm{CO}_{3}\right.$ on $\mathrm{AN}$ and $\mathrm{NaCl}-\mathrm{Na}_{2} \mathrm{CO}_{3}$ on $\mathrm{SN}$ ) were examined.

For the combination GR and $\mathrm{KCl}-\mathrm{NaCl}$, it is possible to eject salt droplets and print simple geometries. Figure 10 shows printed salt parts. Presumably due to the high density change at solidification, part warpage is observable. The other tested salt-substrate combinations did not lead (a)

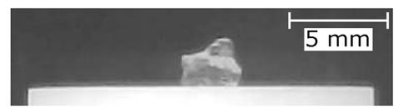

(c)

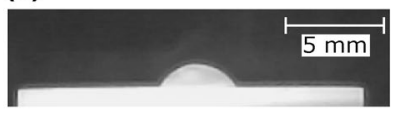

(b)

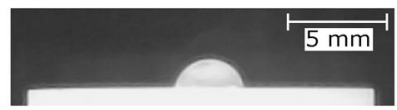

(d)

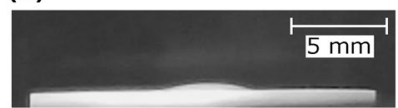

Fig. 9 Long term contact angle measurement of the combination $\mathrm{NaCl}$ on AN. The salt sample is shown before melting (a), after it is completely melted (b) and 10min (c) and 30min (d) at quasi constant temperature copper rod temperature and nitrogen flow rate
Table 5 Tested salt-substrate combinations in the MJT test stand

\begin{tabular}{llll}
\hline & $\mathrm{NaCl}$ & $\mathrm{KCl}-\mathrm{NaCl}$ & $\mathrm{NaCl}-\mathrm{Na}_{2} \mathrm{CO}_{3}$ \\
\hline $\mathrm{AO}$ & & & \\
$\mathrm{AN}$ & $\mathrm{x}$ & $\mathrm{x}$ \\
$\mathrm{GR}$ & & & \\
$\mathrm{GC}$ & & \\
$\mathrm{SN}$ & $\mathrm{x}$ & $\mathrm{x}$ \\
$\mathrm{ZO}$ & & $\mathrm{x}$ \\
\hline
\end{tabular}

to a reliable printing process. The underside of the nozzle is wetted with salt. Nozzles made of AN allowed for short term printing ( $<20 \mathrm{~min}$ ). The results of the long term contact angle measurements suggest that the GR nozzles will also wet after an extended period of time which hinders the further ejection of droplets.

As test geometries we chose the logo of the Technical University of Munich (TUM) as well as a ring-shaped geometry. The printed parts proof the possibility of processing molten salt via MJT. In a future step, the salt parts have to printed on with the build material (e.g. aluminium) in order to function as a support structure. Eventually, the printing of salt parts shall enable the production of more complex parts, such as the one depicted in Fig. 2.

\subsection{Limitation of the contact angle measurements}

The determination of contact angles of molten salt remains a challenging task. Multiple effects influence the measurement of contact angles [7]. The described test stand allows qualitative statements about the wettability. The quantification of (a)

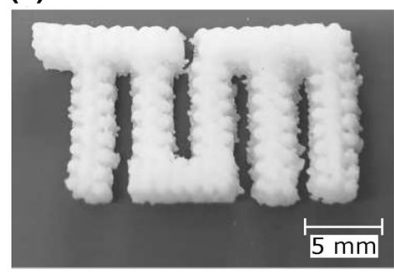

(c)

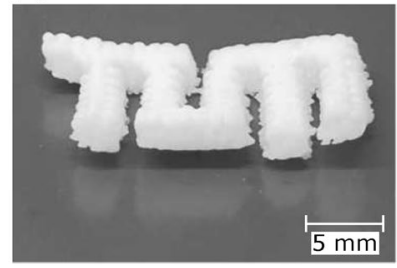

(b)

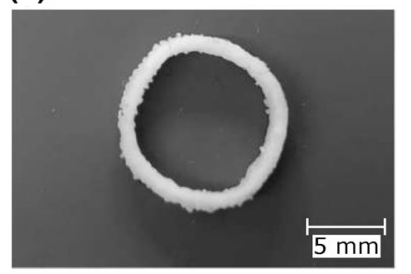

(d)

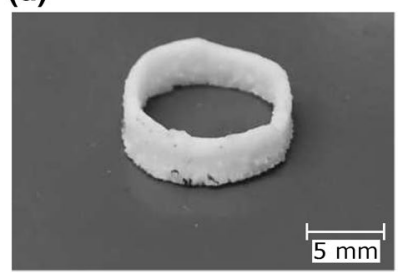

Fig. 10 Material jetted salt parts. A printed logo of the Technical University Munich is shown (a). The logo has a height of approximately $12 \mathrm{~mm}$. Further, a printed salt ring is shown (b). The two salt parts are also depicted from a different perspective in (c) and (d) to show the considerable warpage 
contact angles is limited due to a relatively high statistical range of the results. For more precise measurements, a more direct determination of the droplet temperature is desirable. Further, taking the history of the samples into account seems to be very important, since changing contact angles over exposure time were observed.

\section{Conclusion}

The goal of this work was to find a suitable salt and nozzle material for printing water soluble support structures for a metal MJT process. Since the wetting characteristics are crucial in the printing process, a sessile drop test stand was built to investigate the contact angles of salt melts on various substrate materials. The contact angles of molten salt on ceramic surfaces are typically low. Of the investigated samples, only $\mathrm{KCl}-\mathrm{NaCl}$ in combination with GR showed poor wetting which is important for the printing process. It appears that the wetting properties depend on the combination of both salt and substrate. Nozzles were manufactured out of selected substrate materials and tested in the MJT test stand. For the combination $\mathrm{GR}$ and $\mathrm{KCl}-\mathrm{NaCl}$ it is possible to eject salt droplets and print simple geometries.

The shown possibility of printing salt in a MJT process enables the production of water soluble support structures that can be used to extend the possible part complexity in metal MJT at low effort of rework.

Acknowledgements Funded by the Deutsche Forschungsgemeinschaft (DFG, German Research Foundation), Project Number: 420547518. The authors thank Josef Schweiger, Head of the dental laboratory at the Department of Prosthetic Dentistry at the Ludwig-MaximiliansUniversity Munich and Lithoz $\mathrm{GmbH}$ for the manufacturing of ceramic nozzles as well as Alexander Sanin for his experimental support.

Funding Open Access funding enabled and organized by Projekt DEAL. Funded by the Deutsche Forschungsgemeinschaft (DFG, German Research Foundation), Project Number: 420547518

Data Availability Statement Availability of data and material (data transparency)

\section{Declarations}

Conflict of interest The authors have no conflicts of interest to declare that are relevant to the content of this article.

Open Access This article is licensed under a Creative Commons Attribution 4.0 International License, which permits use, sharing, adaptation, distribution and reproduction in any medium or format, as long as you give appropriate credit to the original author(s) and the source, provide a link to the Creative Commons licence, and indicate if changes were made. The images or other third party material in this article are included in the article's Creative Commons licence, unless indicated otherwise in a credit line to the material. If material is not included in the article's Creative Commons licence and your intended use is not permitted by statutory regulation or exceeds the permitted use, you will need to obtain permission directly from the copyright holder. To view a copy of this licence, visit http://creativecommons.org/licenses/by/4.0/.

\section{References}

1. Wohlers TT (2019) Wohlers report 2019, 3D printing and additive manufacturing. Global State of the Industry, Wohlers Associates, Fort Collins

2. Himmel B, Rumschöttel D, Volk W (2018) Tensile properties of aluminium 4047A built in droplet-based metal printing. Rapid Prototyp J 25(2):427-432

3. Liu Q, Orme M (2001) On precision droplet-based net-form manufacturing technology. Proc Inst Mech Eng Part B J Eng Manuf 215(10):1333-1355

4. Karampelas IH, Vader S, Vader Z, Sukhotskiy V, Verma A, Garg G, Tong M, Furlani E, (2017) Drop-on-demand 3D metal printing. Tech Connect Briefs Inform Electron Microsyst

5. Zhang D, Qi L, Luo J, Yi H, Hou X (2017) Direct fabrication of unsupported inclined aluminum pillars based on uniform micro droplets deposition. Int J Mach Tools Manuf 116:18-24

6. Sepeur S (2008) Nanotechnology: technical basics and applications. Vincentz Network, Hanover

7. Law KY, Zhao H (2016) Surface wetting: characterization, contact angle, and fundamentals. Springer, Cham

8. Weintraub R, Apelblat A, Tamir A (1985) Determination of water content of hygroscopic lithium salts. Anal Chimica Acta $166: 325-327$

9. Miller RR, Smith SH, Williams DD (1971) Solubility of lithium carbonate at elevated temperatures. J Chem Eng Data 16(1):74-75

10. Mills KC (2002) Recommended values of thermophysical properties for selected commercial alloys. Woodhead Publishing, Cambridge

11. Binnewies M, Finze M, Jäckel M, Schmidt P, Willner H, RaynerCanham G (2016) Allgemeine und Anorganische Chemie. Springer, Berlin Heidelberg

12. Dessureault Y, Sangster J, Pelton AD (1990) Coupled phase diagram-thermodynamic analysis of the 24 binary systems, A2CO3$\mathrm{AX}$ and $\mathrm{A} 2 \mathrm{SO} 4-\mathrm{AX}$ Where $\mathrm{A}=\mathrm{Li}, \mathrm{Na}, \mathrm{K}$ and $\mathrm{X}=\mathrm{Cl}, \mathrm{F}, \mathrm{NO} 3$, OH. J Phys Chem Ref Data 19(5):1149-1178

13. Janz GJ (1967) Molten salts handbook. Academic Press, London

14. Jiang Y, Sun Y, Liu M, Bruno F, Li S (2016) Eutectic Na2CO3$\mathrm{NaCl}$ salt: a new phase change material for high temperature thermal storage. Solar Energy Materi Solar Cells 152:155-160

15. Ozeryanaya IN (1985) Corrosion of metals by molten salts in heat-treatment processes. Metal Sci Heat Treat 27(3):184-188

16. Gill CB, Straumanis ME, Schlechten AW (1955) Corrosion of titanium in fused chlorides: formation of pyrosols. J Electrochem Soci 102(1):42

17. Gogotsi YG, Maximova TA, Thümmler F, Lavrenko VA (2012) Corrosion of high-performance ceramics. Springer, Berlin Heidelberg

18. Jacobson NS, Smialek JL, Fox DS (1994) Molten salt corrosion of ceramics. In: Nickel KG (eds) Corrosion of advanced ceramics. NATO Science Series E: (closed), vol 267. Springer, Dordrecht

19. Rumschoettel D, Griebel B, Irlinger F, Lueth TC (2017) A fast pneumatic droplet generator for the ejection of molten aluminum. Pan Pacific Microelectron Symp

20. Fischer SC (2009) Korrosion von polykristallinem Aluminiumoxid (PCA) durch Metalljodidschmelzen sowie deren Benetzungseigenschaften. Forschungszentrum Jülich, Jülich

Publisher's Note Springer Nature remains neutral with regard to jurisdictional claims in published maps and institutional affiliations. 